Article

\title{
Predicting Stormwater Retention Capacity of Green Roofs: An Experimental Study of the Roles of Climate, Substrate Soil Moisture, and Drainage Layer Properties
}

\author{
Antonia Longobardi * ${ }^{\circ}$, Roberta D'Ambrosio $₫$ and Mirka Mobilia $₫$ \\ Department of Civil Engineering, University of Salerno, Via Giovanni Paolo II, 132, 84084 Fisciano SA, Italy; \\ robdambrosio@unisa.it (R.D.); mmobilia@unisa.it (M.M.) \\ * Correspondence: alongobardi@unisa.it
}

Received: 5 November 2019; Accepted: 4 December 2019; Published: 6 December 2019

check for updates

\begin{abstract}
Due to the ever-increasing degree of urbanization, blue and green infrastructures are becoming important tools for achieving stormwater management sustainability in urban areas. Concerning green roofs, although scientists have investigated their behaviors under different climates and building practices, their hydrological performance is still a thought-provoking field of research. An event scale analysis based on thirty-five rainfall-runoff events recorded at a new set of experimental green roofs located in Southern Italy has been performed with the aim of identifying the relative roles of climate, substrate moisture conditions, and building practices on retention properties. The retention coefficient showed a wide range of variability, which could not be captured by neither simple nor multiple linear regression analysis, relating the latter to rainfall characteristics and substrate soil water content. Significant improvements in the prediction of the retention coefficient were obtained by a preliminary identification of groups of rainfall-runoff events, based on substrate soil water content thresholds. Within each group, a primary role is played by rainfall. At the experimental site, building practices, particularly those concerning the drainage layer properties, appeared to affect the retention properties only for specific event types.
\end{abstract}

Keywords: sustainability; hydrological risk; stormwater management; green infrastructures; green roofs

\section{Introduction}

The most recent urbanization dynamics have gradually led cities to deal with an increase in the frequency and severity of urban flood and urban water deterioration [1]. Strategies involving the use of blue and green infrastructures (BGIs) appear; these include essential planning and design actions able to increase the cities' resilience [2,3]. Among the types of BGIs, green roofs (GRs) are a particular type of roofing that allows making the best of the roofs' waterproof surfaces, which amount to up to $40 \%$ of the entire urban impervious area [4]. Air quality improvement, thermal and acoustic building insulation, the effect of reduction in heat islands, stormwater reduction, filtering of polluting substances from stormwater, optimization of urban surfaces, and improvement in urban life quality are a few examples of the multiple benefits that can be achieved at the urban scale after implementation of green roofs $[5,6]$.

With reference to the stormwater management, the GRs appear able to make a significant contribution to the traditional stormwater management technologies during rainfall events by reducing stormwater volume and peak discharge. The retention performance of green roofs appears affected by multiple variables that can basically be divided into two categories: Climate variables $[7,8]$ and design variables $[9,10]$. A typically higher percentage of retention is indeed observed in thicker roofs and 
climate situations characterized by sporadic rains of moderate cumulative volume [11-14]. Climate conditions featuring relatively frequent severe events and changes between prolonged dry and wet seasons, as is typical for the Mediterranean climate type, appear rather critical for management of GRs [15]. However, the number of scientific contributions indicates an extremely variable level of rainwater reduction. GRs appear to reduce total yearly runoff volume by $40 \%$ to $90 \%$, with an important seasonal fluctuation, while the peak flow rate can be even more attenuated, i.e., by $20 \%$ to $90 \%$ [16-19].

Identifying relationships between the GR retention capacities and the characteristics of meteorological and design variables is not generally a simple and successful task. Several authors actually reported on these difficulties [20-22] as well as highlighted the fact that regression analysis is unlikely to always provide an accurate model to predict GR retention for individual precipitation events [7]. The role played by the antecedent substrate moisture conditions—or alternatively, the length of the antecedent dry period-is also uncertain, as for some studies, they are of primary importance $[9,10,23]$, while in some others, only a weak correlation with retention properties has been highlighted [20-22,24].

In this paper benefitted from the findings of a new experimental installation including two extensive test beds located in a typical Mediterranean environment. An event scale analysis based on data from thirty-five rainfall-runoff events over two years was performed to identify the roles of climate, substrate moisture conditions, and building practices on GRs retention properties. Based on the empirical findings, it seems feasible to provide recommendations for a preliminary classification of rainfall-runoff events in order to better explain the GR hydrological behavior and to consequently improve the retention capacity $(\mathrm{RC})$ prediction.

\section{Materials and Methods}

\subsection{The Experimental Site and the Monitoring System}

In January 2017, two extensive green roof test beds $\left(2.5 \mathrm{~m}^{2}\right)$ were installed at the Maritime and Environmental Hydraulic Laboratory of the University of Salerno [25-28]. The two experimental roofs have a total thickness of about $15 \mathrm{~cm}$. They are made up of three layers: The vegetation layer, substrate layer, and drainage layer. A filter mat of non-woven fabric (geotextile made of polyester fiber) is interposed between the substrate and the drainage layer in order to prevent the soil from obstructing the voids between the particles that make up the drainage layer.

The vegetation layer consists of a species of succulent plant called Mesembryanthemum, which is typical of the Mediterranean areas and is considered particularly suitable for facing the specific climatic features (Figure 1a). The substrate layer, with $10 \mathrm{~cm}$ thickness, was made by TRIPLO soil and consisted of a mix of blond peat, Baltic brown peat, zeolites, and simple non-composted vegetable primer (coconut fibers), and was completed with the addition of mineral fertilizer made of organic nitrogen fertilizer (biostimulant algae). Finally, the drainage layer, with $5 \mathrm{~cm}$ depth, was designed differently for the two roofs. In fact, one of them (GR1) is made up of expanded clay aggregate (diameter from 8 to $20 \mathrm{~mm}$ ), while the other (GR2) is made up of a commercial plastic tray (MODI) of $60 \times 60 \times 5 \mathrm{~cm}$; each was characterized by 13 cone-shaped concavities, extruded from their bases and filled with expanded clay aggregate (Figure $1 b, c)$.

Laboratory experiments were conducted to characterize the substrate and drainage layer properties. For the substrate layer, a dry unit weight of about $3.63 \mathrm{kN} / \mathrm{m}^{3}$, a porosity $\mathrm{n}$ of about $63 \%$, and a water holding capacity of about $37 \%$ were found. For the drainage layer, a dry unit weight of about 5.84 $\mathrm{kN} / \mathrm{m}^{3}$ for the expanded clay aggregate, a porosity $\mathrm{n}$ of about $77 \%$, and a water holding capacity of about $34 \%$ were found, which generated a $6.7 \mathrm{~L} / \mathrm{m}^{2}$ retention capacity in the case of the GR1 site (5 $\mathrm{cm}$ expanded clay aggregate depth). In the case of the GR2 site ( $5 \mathrm{~cm}$ height commercial plastic trays filled with expanded clay aggregate), a $7.9 \mathrm{~L} / \mathrm{m}^{2}$ retention capacity was found. Given the similarity in the substrate layer for the two sites, it can be assumed that the GR2 system is characterized by a moderately larger retention capacity (about 18\%) compared to GR1. 

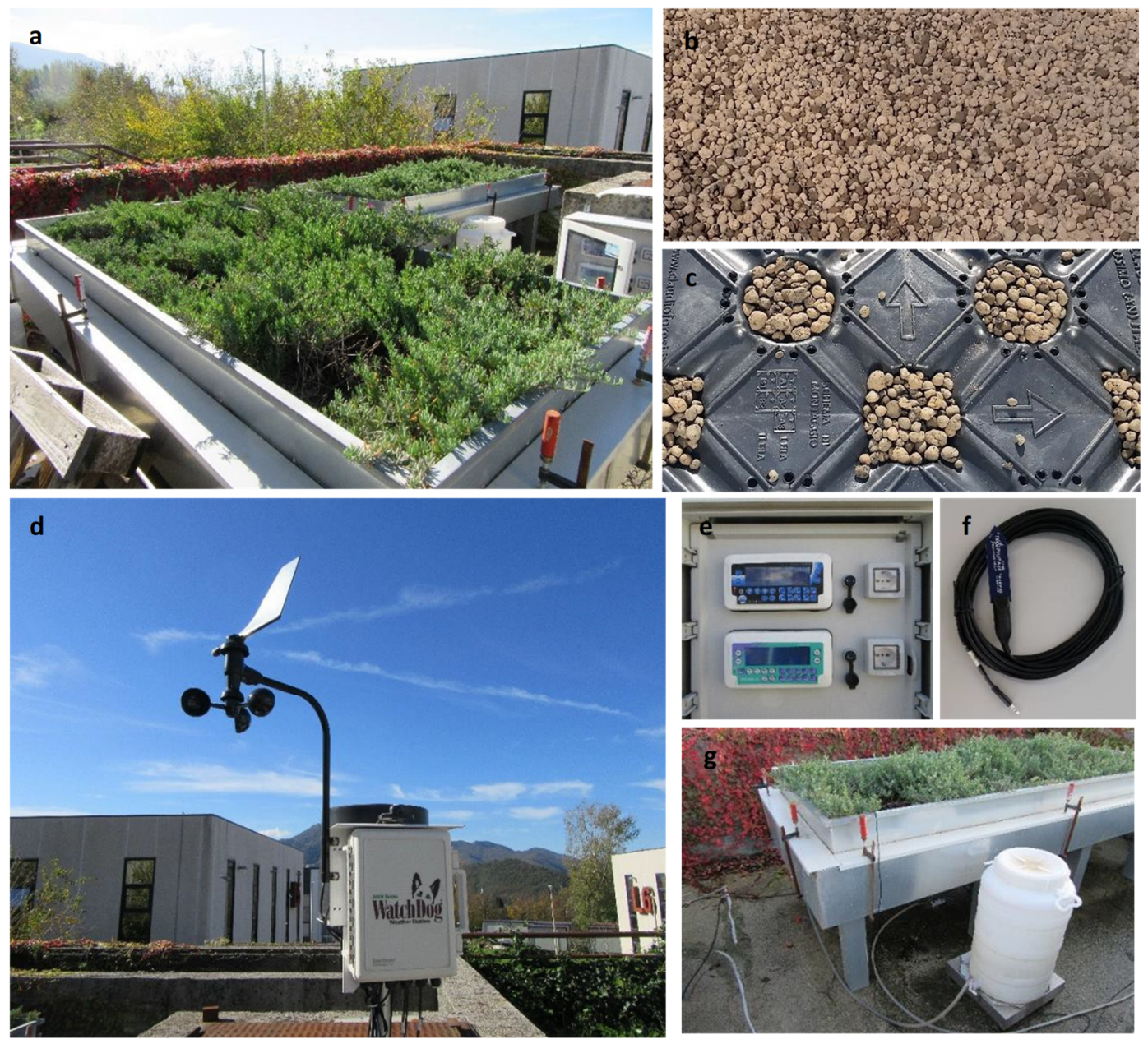

Figure 1. (a) The experimental site overview; (b) expanded clay drainage layer (GR1); (c) plastic trays filled with expanded clay drainage layer (GR2); (d) meteorological station; (e) scale control boards; (f) soil moisture sensor; (g) runoff collection system.

The experimental site was monitored ( 5 min time step) by a weather station, Watchdog 2000 Series (Model 2550), which includes: Tipping bucket rain gauge, hygrometer for air humidity measurement, pyranometer with silicon sensor (spectral field $300-1100 \mathrm{~nm}$, range 1-1250 W/m²) for solar radiation measurements, and an anemometer for wind speed and direction measurements (Figure 1d). Runoff from the experimental sites was collected in circular-shaped tanks located above digital calibrated scales in order to measure (5 min time steps) the stormwater volume (Figure 1e,g).

Volumetric water content within the substrate layer was monitored with the use of the commercial moisture sensor SM 100 [29]. It is shaped as a thin plate with a sharp tip at the bottom. The sensor has a thickness of $3 \mathrm{~mm}$, a height of $60 \mathrm{~mm}$, and a width of $20 \mathrm{~mm}$, and was installed vertically (Figure 1f). The sensor is made up of two electrodes that act as a capacitor, with the surrounding soil serving as the dielectric. An $80 \mathrm{MHz}$ oscillator drives the capacitor and a signal proportional to the soil's dielectric permittivity is converted to the output signal.

In order to achieve a greater accuracy, soil-specific calibration was performed in the laboratory, relating the capacitance sensor's electronic readings to the actual volumetric water content, according to the product manual specification [29]. Volumetric moisture content during calibration ranged between $4 \%$ and $60 \%$. The actual volumetric water content at each calibration condition was measured by the gravimetric method with oven drying. The method involves weighing a moist sample, oven drying it at $105^{\circ} \mathrm{C}$ for $24-48 \mathrm{~h}$, reweighing, and calculating the mass of water lost as a percentage of the mass of the dried soil. 


\subsection{Long Term and Event Scale Climate Characterization}

The experimental roofs are located in an outdoor area close to the Maritime and Environmental Hydraulics Laboratory of the University of Salerno (40.770535, 14.789522, $245.50 \mathrm{~m}$ a.s.l.). The average annual temperature is $16.4^{\circ} \mathrm{C}$, while the average annual rainfall is $1307.09 \mathrm{~mm}$. In August, the hottest month of the year, the average temperature is $24.7^{\circ} \mathrm{C}$, while in February, the coldest month, there is an average temperature of $8.1^{\circ} \mathrm{C}$. The plot in Figure 2 (left panel) shows the monthly average distribution of rainfall and temperatures at the experimental site. Rainfall and air temperature are in antiphase with each other. The largest fraction of annual rainfall occurs indeed in the period of lowest temperature and lowest evapotranspiration losses, when the green roof is likely characterized by the lower retention capacity.
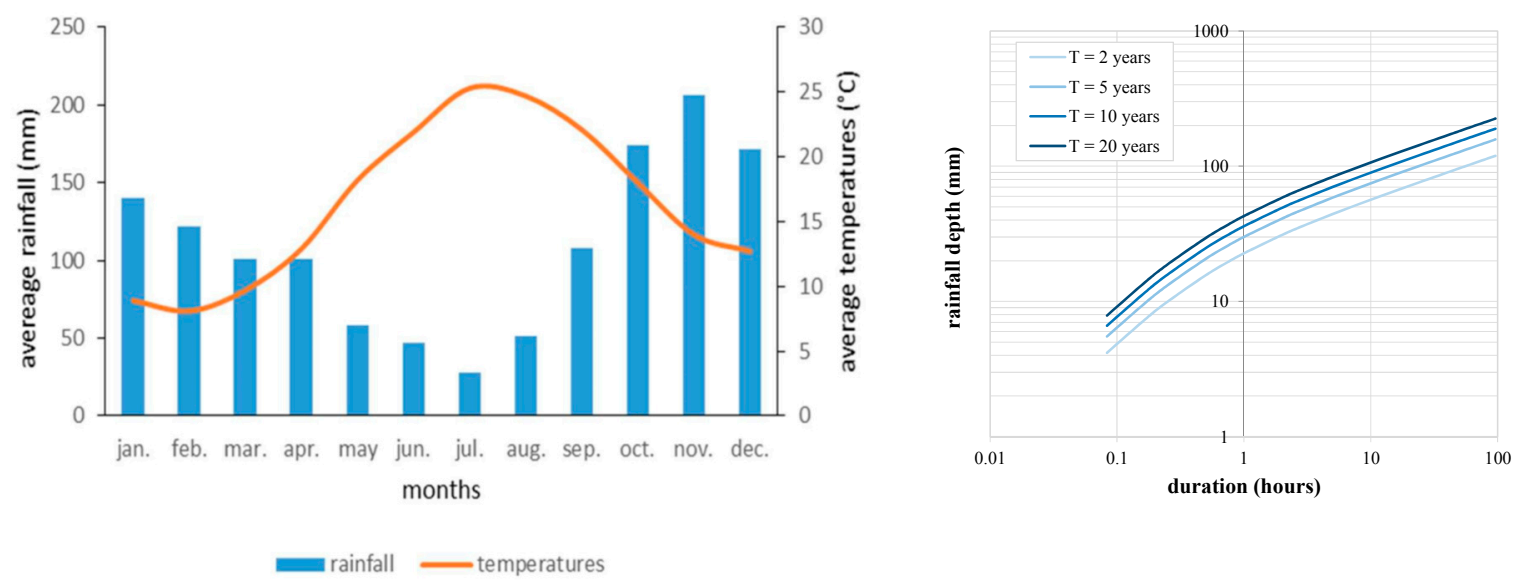

Figure 2. Left panel: Monthly average rainfall $(\mathrm{mm})$ and temperature $\left({ }^{\circ} \mathrm{C}\right)$ at the experimental site. Right panel: Rainfall depth-duration-frequency relationships at the experimental site for 2, 5, 10, and 20 years return period $\mathrm{T}$.

For an event scale characterization, rainfall depth-duration relationships were estimated according to a regional procedure, where the cumulate precipitation quantile estimation $h(F)$, with non-exceedance probability $\mathrm{F}$, was obtained by combining the quantile function of the fitted distribution, $g(F)$, commonly referred to as regional growth curve, with the index value, $h_{m}$, by using the following expression:

$$
h(F)=h \mathrm{~m} \cdot g(F) .
$$

To provide the relation between the return period $\mathrm{T}$ and the non-exceedance probability $F$ :

$$
T=\frac{1}{1-F}
$$

Equation (1) can be written as:

$$
h\left(1-\frac{1}{T}\right)=h \mathrm{~m} \cdot g\left(1-\frac{1}{T}\right) .
$$

An approximate relation between the growth coefficient for a given value of $T, g(T)$, and the value of $T$ itself was calibrated for extreme rainfall for the homogeneous region to which the experimental site belongs [30]. Rainfall depth-duration relationships for $T=2,5,10$, and 20 years were estimated for the purpose of further comparison with the rainfall events that occurred at the experimental site. Results are illustrated in Figure 2 (right panel). 


\subsection{Methodology}

The event scale analysis concerned 35 rainfall-runoff events that occurred in a period between July 2017 and April 2019. Measurements collected during the first six months of the monitoring period, from January 2017 to July 2017, were not taken into account, because the system was considered to be at an early stage and not fully or properly working. To avoid mutual dependence of consecutive rainfall-runoff events, an antecedent dry water period of at least $7 \mathrm{~h}$ between two consecutive rainfall events was set as a threshold to select independent events, according to the relevant literature $[20,21,23,24]$.

Starting from the raw data, the cumulative rainfall for each selected event, the duration, the maximum 5 min peak intensity, and the return period were evaluated. The runoff generated by each of the considered rainfall events was analyzed in order to study the hydrological behavior, summarized by the retention capacity $(R C)$ :

$$
\mathrm{RC}=1-(\mathrm{V} \text { runoff }) /(\mathrm{V} \text { rainfall }),
$$

where $\mathrm{V}$ is the total volume produced during each event.

Volumetric soil water content (VW \%) within the substrate layer, collected at a 5 min step through the soil moisture capacitance probes and converted to actual values through the calibration relationship as previously mentioned, were used to characterize the initial hydrological conditions for each specific event.

In order to assess the relative roles of climate features, substrate soil moisture content, and drainage layer properties on the prediction of green roofs' stormwater retention capacity, the correlation between the mentioned variables was investigated within a multi-step regression approach for both GR1 and GR2. Estimates from the optimal regression approach and observation were compared to measure the ability of the regression tools to predict the GR's retention coefficient. Results are reported in the following.

\section{Results}

The quantitative characterization of the analyzed rainfall events is reported in Table 1. It is possible to observe that the duration of the rain events ranges from a minimum of $35 \mathrm{~min}$ to a maximum of about 3 days. As for the cumulative rainfall, it goes from a minimum value of $0.50 \mathrm{~mm}$ to a maximum value of $122.17 \mathrm{~mm}$, while, regarding the peak five minutes' intensity (intended as the maximum rainfall value in a range of $5 \mathrm{~min}$ ), it goes from a minimum of $0.25 \mathrm{~mm} / 5 \mathrm{~min}$ to a maximum of $6.604 \mathrm{~mm} / 5 \mathrm{~min}$.

Table 1. Rainfall properties at the event scale.

\begin{tabular}{cccc}
\hline \multirow{2}{*}{ Event } & Duration & Cumulative Rainfall & Peak Intensity \\
\cline { 2 - 4 } & $\mathbf{m i n}$ & $\mathbf{m m}$ & $\mathbf{m m} / \mathbf{5} \mathbf{~ m i n}$ \\
\hline $25 / 07 / 2017$ & 50 & 1.78 & 2.54 \\
$26 / 07 / 2017$ & 345 & 22.09 & 4.31 \\
$07 / 09 / 2017$ & 545 & 6.60 & 1.52 \\
$22 / 10 / 2017$ & 2235 & 48.51 & 6.60 \\
$21 / 01 / 2018$ & 625 & 26.16 & 1.77 \\
$01 / 02 / 2018$ & 1140 & 7.11 & 0.76 \\
$12 / 02 / 2018$ & 923 & 4.83 & 0.50 \\
$13 / 02 / 2018$ & 40 & 0.76 & 0.25 \\
$14 / 02 / 2018$ & 195 & 4.82 & 0.25 \\
$18 / 02 / 2018$ & 1735 & 11.17 & 0.25 \\
$20 / 02 / 2018$ & 1020 & 11.43 & 0.50 \\
$02 / 03 / 2018$ & 160 & 3.30 & 1.01 \\
$03 / 03 / 2018$ & 635 & 11.43 & 0.50 \\
$04 / 03 / 2018$ & 4565 & 59.69 & 3.30 \\
\hline
\end{tabular}


Table 1. Cont.

\begin{tabular}{cccc}
\hline \multirow{2}{*}{ Event } & Duration & Cumulative Rainfall & Peak Intensity \\
\cline { 2 - 4 } & min & mm & mm/5 min \\
\hline $09 / 04 / 2018$ & 275 & 6.35 & 0.76 \\
$12 / 04 / 2018$ & 450 & 0.50 & 0.25 \\
$17 / 04 / 2018$ & 290 & 5.84 & 2.03 \\
$04 / 05 / 2018$ & 465 & 1.52 & 0.25 \\
$09 / 05 / 2018$ & 35 & 1.01 & 0.25 \\
$15 / 05 / 2018$ & 630 & 28.44 & 5.08 \\
$17 / 05 / 2018$ & 50 & 0.51 & 0.25 \\
$22 / 05 / 2018$ & 1730 & 122.17 & 5.08 \\
$05 / 10 / 2018$ & 135 & 2.79 & 0.25 \\
$14 / 10 / 2018$ & 335 & 3.04 & 0.25 \\
$22 / 10 / 2018$ & 850 & 44.7 & 3.04 \\
$27 / 10 / 2018$ & 175 & 4.82 & 1.77 \\
$28 / 10 / 2018$ & 165 & 7.11 & 0.76 \\
$30 / 10 / 2018$ & 55 & 1.01 & 0.50 \\
$22 / 11 / 2018$ & 330 & 1.52 & 0.50 \\
$03 / 12 / 2018$ & 1560 & 13.46 & 1.01 \\
$08 / 12 / 2018$ & 20 & 2.79 & 1.52 \\
$11 / 03 / 2019$ & 385 & 32.00 & 1.77 \\
$12 / 04 / 2019$ & 100 & 5.33 & 0.50 \\
$22 / 04 / 2019$ & 85 & 3.55 & 0.25 \\
$22 / 04 / 2019$ & 85 & 3.55 & 0.50 \\
\hline
\end{tabular}

In addition to rainfall properties, runoff and retention capacity values also vary widely among the analyzed events (Table 2). Retention capacity ranges between $4 \%$ and $100 \%$ in the case of GR1 (expanded clay aggregate drainage), with an average value of $69 \%$. It ranges between $11 \%$ and $100 \%$ in the case of GR2 (modular tray panels drainage) with an average value of $67 \%$.

Table 2. Initial substrate volumetric soil water content VW (VW1 and VW2 refer respectively to the GR1 and GR2) and retention coefficient RC (RC1 and RC2 refer respectively to the GR1 and GR2) at the event scale.

\begin{tabular}{ccccc}
\hline \multirow{2}{*}{ Event } & VW1 & VW2 & RC1 & RC2 \\
\cline { 2 - 5 } & \% & \% & \% & \% \\
\hline $25 / 07 / 2017$ & 5.93 & 7.12 & 83 & 88 \\
$26 / 07 / 2017$ & 8.43 & 9.44 & 71 & 69 \\
$07 / 09 / 2017$ & 5.78 & 3.21 & 78 & 78 \\
$22 / 10 / 2017$ & 7.93 & 10.75 & 49 & 57 \\
$21 / 01 / 2018$ & 29.90 & 32.65 & 31 & 18 \\
$01 / 02 / 2018$ & 14.85 & 18.25 & 84 & 80 \\
$12 / 02 / 2018$ & 23.88 & 27.62 & 83 & 80 \\
$13 / 02 / 2018$ & 26.23 & 29.12 & 91 & 80 \\
$14 / 02 / 2018$ & 26.28 & 29.30 & 81 & 77 \\
$18 / 02 / 2018$ & 24.64 & 27.37 & 82 & 78 \\
$20 / 02 / 2018$ & 29.89 & 31.06 & 20 & 29 \\
$02 / 03 / 2018$ & 32.16 & 32.24 & 38 & 40 \\
$03 / 03 / 2018$ & 32.05 & 34.09 & 18 & 39 \\
$04 / 03 / 2018$ & 32.04 & 34.06 & 4 & 11 \\
$09 / 04 / 2018$ & 19.36 & 22.77 & 81 & 81 \\
$12 / 04 / 2018$ & 18.56 & 21.31 & 100 & 100 \\
$17 / 04 / 2018$ & 8.85 & 9.36 & 85 & 81 \\
$04 / 05 / 2018$ & 5.63 & 4.00 & 97 & 79 \\
$09 / 05 / 2018$ & 21.74 & 17.00 & 95 & 86 \\
$15 / 05 / 2018$ & 7.89 & 8.35 & 76 & 72 \\
\hline
\end{tabular}


Table 2. Cont.

\begin{tabular}{ccccc}
\hline \multirow{2}{*}{ Event } & VW1 & VW2 & RC1 & RC2 \\
\cline { 2 - 5 } & $\mathbf{\%}$ & $\mathbf{\%}$ & $\mathbf{\%}$ & $\mathbf{\%}$ \\
\hline $17 / 05 / 2018$ & 25.81 & 25.69 & 100 & 85 \\
$22 / 05 / 2018$ & 7.76 & 8.60 & 58 & 53 \\
$05 / 10 / 2018$ & 9.42 & 6.13 & 86 & 76 \\
$14 / 10 / 2018$ & 8.79 & 7.83 & 90 & 80 \\
$22 / 10 / 2018$ & 7.42 & 8.05 & 64 & 66 \\
$27 / 10 / 2018$ & 6.44 & 7.29 & 84 & 79 \\
$28 / 10 / 2018$ & 7.77 & 7.83 & 84 & 74 \\
$30 / 10 / 2018$ & 20.05 & 15.01 & 89 & 83 \\
$22 / 11 / 2018$ & 25.24 & 18.06 & 75 & 75 \\
$03 / 12 / 2018$ & 22.00 & 27.13 & 49 & 51 \\
$08 / 12 / 2018$ & 18.77 & 22.16 & 86 & 80 \\
$11 / 03 / 2019$ & 1.78 & 3.66 & 63 & 66 \\
$12 / 04 / 2019$ & 32.53 & 28.60 & 26 & 38 \\
$22 / 04 / 2019$ & 5.67 & 8.09 & 91 & 87 \\
\hline
\end{tabular}

As it is well known how the soil water content or relevant proxies can strongly impact the hydrological response of a particular system to a rainfall event, it was considered appropriate to first investigate the experimental relationship between retention capacity (RC) and soil moisture content within the substrate layer prior to the rainfall event occurrence (VW \%) (Figure 3a).
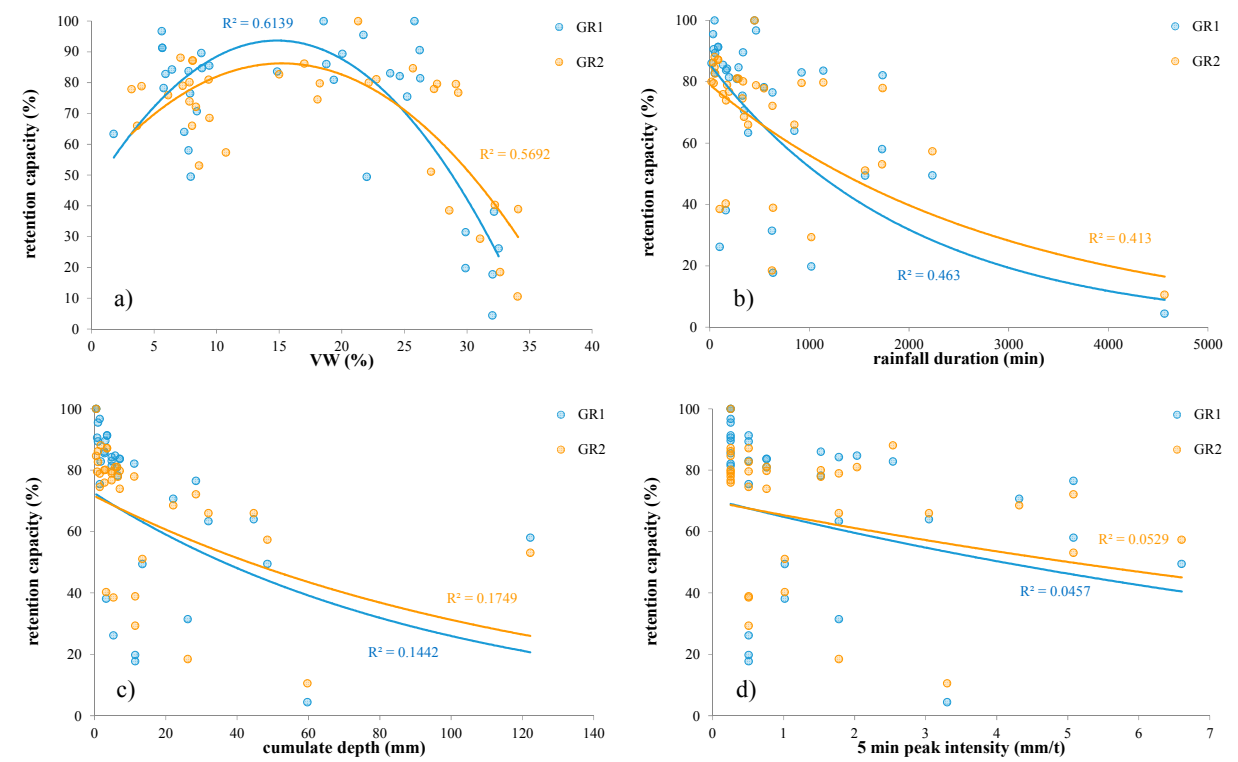

Figure 3. Retention capacity dependence on initial soil water content VW (a), rainfall duration (b), cumulative depth (c), and rainfall intensity (d).

Contrary to what is conceptually expected, but as it is quite common in the literature because of the nature of experimental data, RC showed a broad variability for both GR1 and GR2, which unfortunately, both at the first visual inspection and by regression models, has not been justified by the soil moisture VW values. A polynomial regression between VW and RC only explains about $60 \%$ of the RC variance for both GR1 and GR2. While in fact a reduction of the retention capacity values (lower than $40 \%$ ) is detectable for the higher soil water contents (larger than $35 \%$ ), there is a large range of $\mathrm{VW}$, between $5 \%$ and $30 \%$, where the values of RC assume apparently random values between $40 \%$ and $100 \%$. In addition to the initial substrate soil water content, according to the correlation coefficient 
of the regression models (Figure $3 \mathrm{~b}-\mathrm{d}$ ), rainfall properties also do not appear to adequately explain the $\mathrm{RC}$ variance, as confirmed by similar literature studies.

Multiple regression approaches have also been calibrated for both GR1 and GR2, where all of the considered variables are accounted for:

$$
\begin{array}{lc}
\mathrm{RC}=-1.12 \mathrm{DUR}-1.82 \mathrm{DEPTH}-0.27 \mathrm{PEAK}+0.01 \mathrm{VW}+97.24 & \text { GR1 } \\
\mathrm{RC}=-1.53 \mathrm{DUR}-4.32 \mathrm{DEPTH}-0.21 \mathrm{PEAK}+0.01 \mathrm{VW}+109.62 & \text { GR2 }
\end{array}
$$

with DUR for rainfall duration, DEPTH for cumulative rainfall, PEAK for 5 min peak intensity, and VW for volumetric water content. The explained variance associated with each of them is still relatively poor, amounting to about $56 \%$ and $57 \%$ respectively for GR1 and GR2.

A more detailed investigation of the scatter plot between RC and VW-illustrated in Figure 3-reveals how runoff events show a tendency to distribute themselves into three distinct groups according to VW thresholds (Figure 4). A first group, group A, is characterized by events with an intermediate initial soil water content of between $15 \%$ and $35 \%$, and a considerable retention capacity of above $75 \%$, and of about $86 \%$ on average. A second group, group B, is characterized by events with low initial soil water content of between $5 \%$ and $15 \%$, and a highly variable retention capacity between $50 \%$ and $100 \%$. A third group, group C, is characterized by a high soil water content of more than $30 \%$, and a retention capacity that never exceeded $50 \%$.

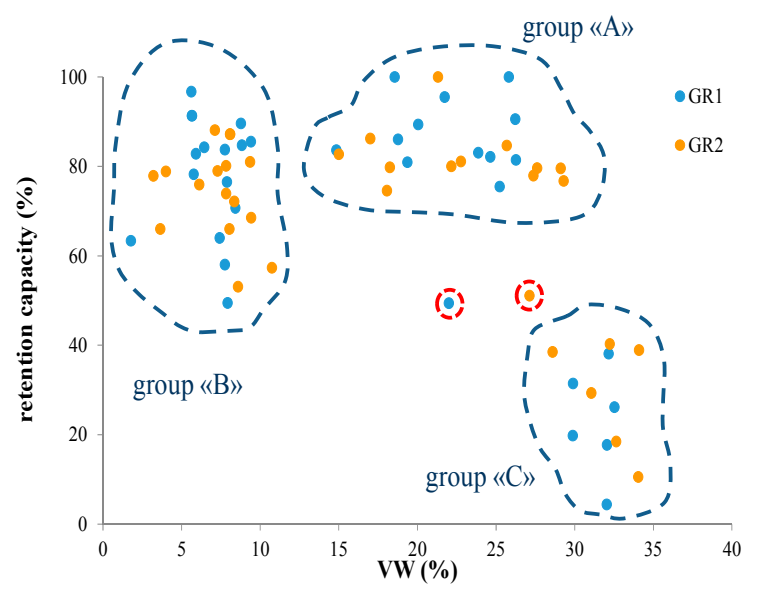

Figure 4. Delineation of groups of runoff events on the basis of initial VW threshold values. Red-shaded circles represent the single events which represent an exception to the general grouping rules.

These findings of the empirical analysis lead to the idea that the relationships between the retention capacity, the initial soil water content, and (in general) the hydrological response at the investigated experimental site appears to be governed by VW thresholds. As shown later, points that belong to each of the outlined groups appear to share particular relationships that link the hydrological response $\mathrm{RC}$ to certain characteristics of precipitation. Those relationships are different for each group and also for each building practice.

Further analyzing the relationships between the initial substrate soil water content and the retention capacity, it was understood that all of the rainfall-runoff events belonging to the first group, group A, resulted in being characterized by a cumulative rainfall value of less than $11.2 \mathrm{~mm}$ and peak intensity lower than $0.762 \mathrm{~mm} / 5 \mathrm{~min}$. These events, about $40 \%$ of total analyzed events, even though they do not generate large volumes of rainwater and are therefore irrelevant as regards the quantitative management issues, are of considerable importance for stormwater quality management. In fact, in many cities around the world, small stormwater events are drained straight into urban streams, causing major ecological issues; the high retention observed in this experimental study could provide an indication on how to lower the frequency of such flows. 
In the case of group A, the hydrological behavior of the green roof seems not to be influenced by the initial state of the water content, further returning a very moderate variability of the retention coefficient. For this particular group, GR1 appears to have a moderately better hydrological performance, with average RC values of about $86 \%$, compared to GR2, characterized by average RC values of about $80 \%$. No significant relationship was found for this group between the retention coefficient and the remaining parameters describing the characteristics of the rainfall.

An exception to this grouping is represented by a single event that occurred on 3 December 2018 (Figure 4, red dashed circles), which, according to the initial VW values, should belong to group A, but which shows significantly lower retentions compared to this group, most likely due to a cumulative rainfall and a rainfall peak intensity that exceed the thresholds identified for group A (13.46 $\mathrm{mm}$ and $1.01 \mathrm{~mm} / 5 \mathrm{~min}$, respectively).

As the second group of events, group B, is characterized by low initial water content of the substrate soil layer (between $5 \%$ and $15 \%$ ), they can significantly reduce the stormwater volumes. They represent the most frequent types of events at the experimental site, as they amount to $45 \%$ of the total analyzed events. A high variability is highlighted for the values of the retention coefficient, which does not appear strongly dependent on initial substrate soil moisture content, but can be actually explained according to the characteristics of the rainfall events, as illustrated in the left panel of Figure 5a-c.

As a general trend, the GR retention capacities related to this type of event (group B) decrease as the duration (Figure 5a), the cumulative depth (Figure $5 \mathrm{~b}$ ), and the precipitation intensity increase (Figure 5c). A regression analysis found a negative exponential relationship between the retention properties and the rainfall duration and cumulative volume. This circumstance would indicate significant changes in the GR retention capacities in the case of short and moderate rainfall events. A linear relation was instead found between retention properties and peak $5 \mathrm{~min}$ intensity. The Pearson correlation coefficients of the regression models, illustrated in Figure $5 b$, showed that the cumulative rainfall volume appeared to be the best predictor for GR retention properties within this specific group B (explained variance of about $80 \%$ for both GR1 and GR2).

According to the quantitative estimation and the regression analysis, the difference between the GR1 and GR2 retention coefficients is negligible in the case of group B, amounting to about $7 \%$ on average (minimum difference $0.3 \%$, maximum difference $11.7 \%$ ). It is also evident that the major differences between GR1 and GR2 are observed for minor events. As the severity of the rainfall events increases, the retention coefficients for GR1 and GR2 approach similar values.

The third group of events, group C (Figure 4), represents the set of runoff events characterized by the lower retention performances associated with the higher substrate soil water content prior to the triggering rainfall event. They represent the least frequent type of event at the experimental site, as they amount only to $15 \%$ of the total analyzed events. A larger number of events would certainly have given greater significance to the empirical analysis but, probably due to the very fast vertical drainage process within the substrate layer, GR systems are very unlikely to persist in the state of high substrate soil water content.

As in the case of group B, a high variability is highlighted for the values of the retention coefficient, never larger than $50 \%$, which does not appear strongly dependent on initial substrate soil moisture content but can be actually explained according to the characteristics of the rainfall events, as illustrated in the right panel of Figure 5a-c. Also in this case, the GR retention capacities related to this type of event (group C) decrease as the duration (Figure 5a), the cumulative depth (Figure 5b), and the precipitation intensity increase (Figure 5c). A regression analysis found a negative exponential relationship between the retention coefficients and all of the considered rainfall properties, included the $5 \mathrm{~min}$ peak intensity. Again, this circumstance would indicate significant changes in the GR retention capacities in the case of short and moderate rainfall events, as well as in the case of high prior VW. According to the Pearson correlation coefficients of the regression models illustrated in Figure $5 \mathrm{a}, \mathrm{b}$, both the rainfall duration (explained variance of about $70 \%$ and $67 \%$ respectively for GR1 and GR2) and the cumulative rainfall 
volume (explained variance of about 59\% and 86\% respectively for GR1 and GR2) appeared to be the best predictors for GR retention properties within group C.

Contrarily to what occurs in the case of group B, a non-negligible difference between the GR1 and GR2 retention coefficients can be detected from the regression analysis, amounting to about $26 \%$ on average, with GR2 showing the better hydrological performances. As previously discussed, based on the results of laboratory experiments, assuming the same substrate layer building practices for each of the test beds, the differences in the GRs' retention properties could be ascribed to the differences in the drainage layer building practices. It is likely that in the case of high initial VW, contrarily to what occurs in the case of low initial VW, the faster drainage from the substrate to the drainage layer sees the drainage layer largely involved in the retention process. Congruently, the GR2, which has a larger retention capacity than the GR1, exhibits the best performance. The differences between the retention capacities of the two test beds, measured in the laboratory, amount to around 18\%; however, they could probably be larger, considering the "storage" effect that the MODI tray panel generates because of its shape (the difference could increase up to $34 \%$ in cases where the MODI plastic tray is not filled with the expanded clay aggregate). Differences between the hydrological performances of GR1 and GR2 are almost the same regardless of the rainfall event characteristics, with a negligible larger difference in the case of larger events.

\section{GROUP “B”}
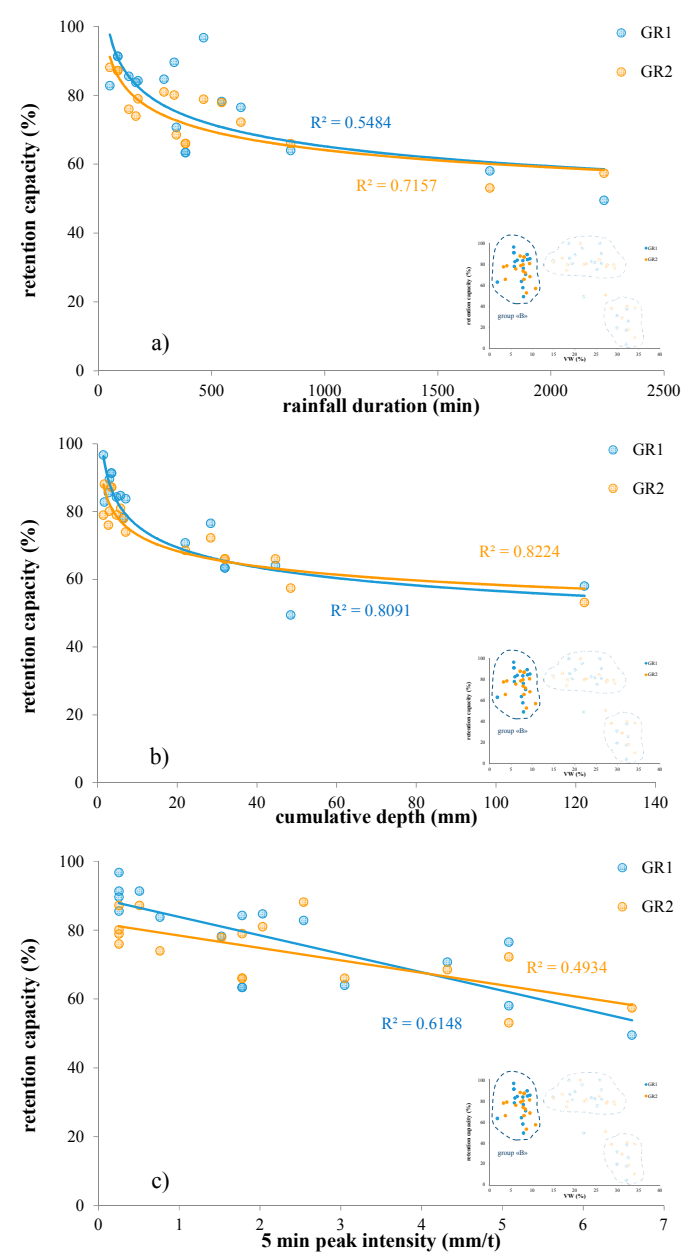

GROUP “C”
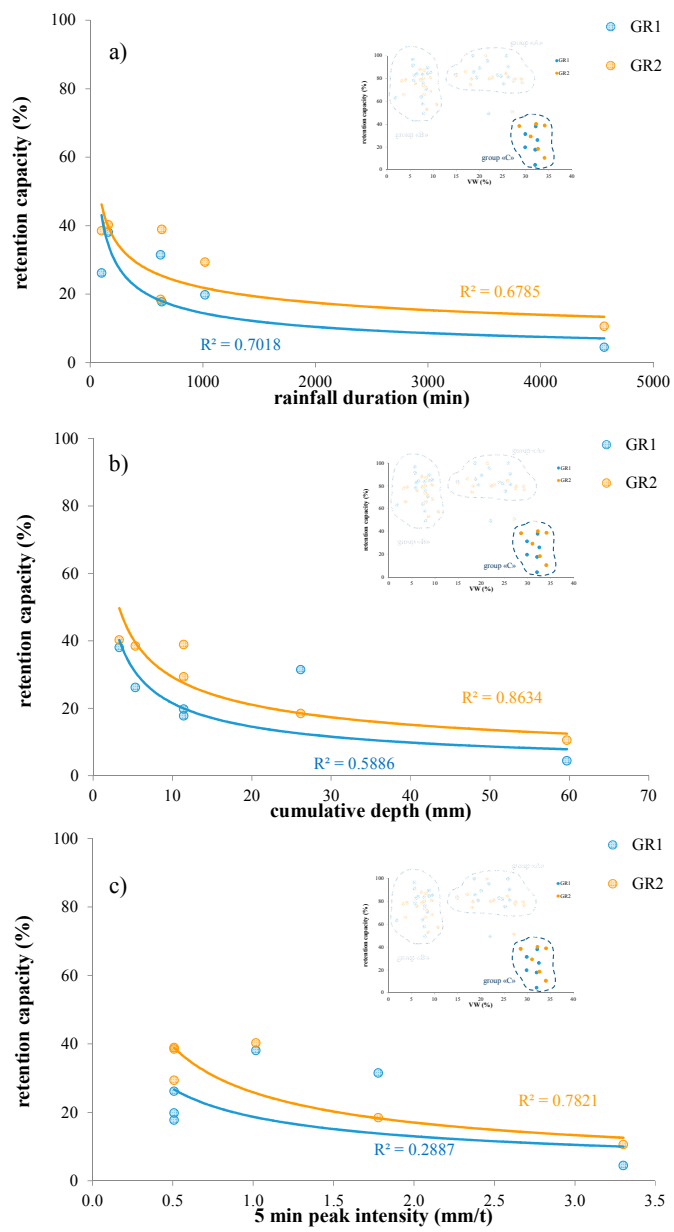

Figure 5. Relationships between retention capacity and rainfall duration, cumulative depth, and peak 5 min intensity. Left panel: Group B (soil moisture content between 5-15\%). Right panel: Group C (soil moisture content $>30 \%$ ). 
Figure 6a displays the rainfall depth vs. the duration of the analyzed events along with the regional depth-duration-frequency curves. The events that occurred do not appear particularly severe. They are indeed clearly bounded by a two year return period rainfall depth-duration curve, with an exception for the 22 May 2018 event, for which the maximum cumulative rainfall of about $122 \mathrm{~mm}$ is characterized by a return period of about 10 years.

Rainfall severity, measured through the rainfall return period, also appears to play a role in the variability of the retention coefficient. For each of the analyzed events, the growth coefficient for each event was assessed and plotted against the corresponding retention coefficient for both GR1 and GR2, as represented in Figure 6b,c. If the groups of the events with initial soil moisture higher than 30\% is excluded from the analysis (group C), for both GR1 and GR2, the retention coefficients appear to decrease with the increasing value of $\mathrm{g}(\mathrm{T})$, that is, for increasing $\mathrm{T}$. The retention coefficients of GR1 and GR2 for the severe event on 22 May 2018 were $58 \%$ and 53\%, respectively.

(a)

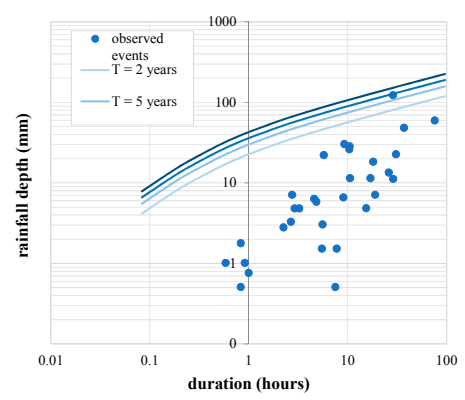

(b)

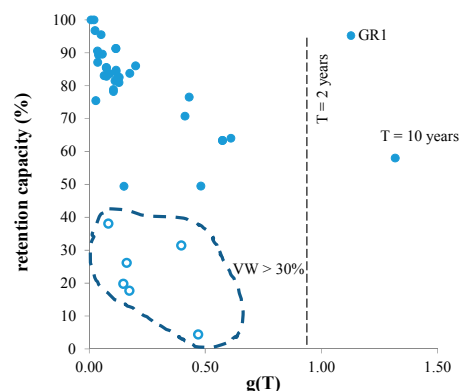

(c)

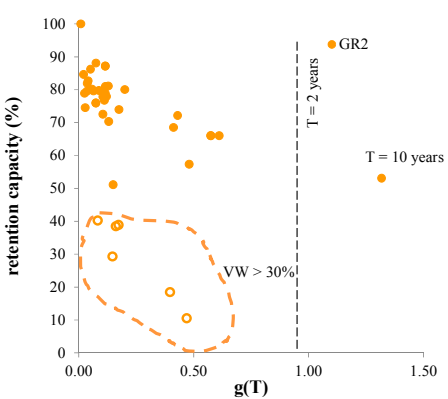

Figure 6. (a) Rainfall depth-duration intensity relationships at the experimental site for return period T of 2, 5, 10, and 20 years. Shaded circles represent the analyzed rainfall events. (b) Retention coefficient for GR1 and (c) retention coefficient for GR2 as a function of the rainfall growth coefficient $\mathrm{g}(\mathrm{T})$.

To measure the reliability of the idea that the identification of homogeneous rainfall-runoff event groups can help improve the prediction of the RC in a regressive approach, the empirical relationships which link the RC values to the climatic variables-as represented in Figure 5-have been used to predict the value of the $\mathrm{RC}$ for each event belonging to the relevant group. The results are shown in Figure 7 for both GR1 and GR2.
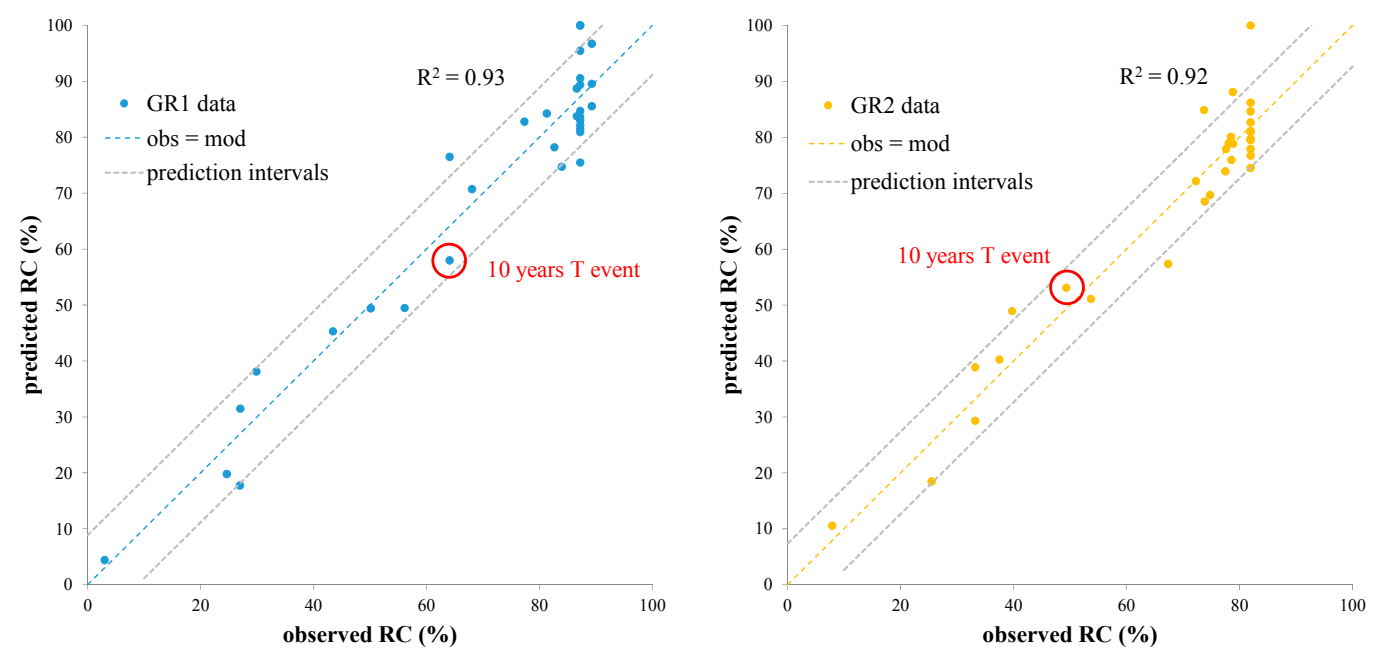

Figure 7. Comparison between observed and predicted retention coefficients at GR1 (left panel) and GR2 (right panel). Prediction intervals at 5\% confidence level are plotted. 
The comparison between the predicted and observed data, together with the large explained variance $\left(R^{2}=0.93\right.$ for GR1 and $R^{2}=0.92$ for GR2) and the prediction intervals ( $5 \%$ significance level) represent a validation of the proposed approach, also regarding the prediction in the case of events characterized by a high return period, evidencing the effectiveness of RC prediction from rainfall data with a prior identification of groups of similar hydrological behaviors.

\section{Conclusions}

Starting from two years of data collected at two recently installed experimental extensive green roof test beds located in Southern Italy, the hydrological performance of such infrastructure was studied. Through the joint analysis of rainfall event characteristics, substrate soil water content prior to the triggering rainfall event, and building practices, an empirical rainfall-runoff analysis of 35 selected events was performed, highlighting the role that each of the mentioned variables has on the GRs' retention properties.

Uncertainty in the application of simple or multiple regression approaches and in the role played by the VW on RC prediction has been confirmed by the present study. The dependence of RC on VW does not appear strongly functional, but is important to the a priori identification of groups of rainfall-runoff events, which leads to an improvement in the regression analysis for RC prediction. In particular, based on VW thresholds, two groups were identified for the case study: Group B with low initial moisture content (between $5 \%$ and $15 \%$ ) and group $C$ with a high initial moisture content (>30\%). Within each group, the prediction of RC values was performed with respect to the specific characteristics of the rain events. A third group A is also outlined, for which the relation of RC with VW totally disappears. It can be identified with a rainfall depth threshold of $11.2 \mathrm{~mm}$ and a peak intensity threshold of $0.762 \mathrm{~mm} / 5 \mathrm{~min}$, and is characterized by an almost constant $R C$ value.

The functional relationships that relate the $\mathrm{RC}$ coefficients to the rainfall properties have a different calibration for each group, but all describe a tendency to the reduction of retention properties for large events (long duration, high cumulate depth and rainfall intensity) and mainly see the cumulative depth of rainfall as the best predictor for RC estimation, with an explained variance of about $80 \%$.

Furthermore, the functional relationships that relate the RC coefficients to the rainfall properties appear different within the same group for GR1 and GR2, highlighting the role played by the drainage layer building practices on the GRs' retention properties. In fact, since the two test beds are characterized by the same vegetation layer, substrate layer depth, and hydraulic properties, the differences in the $\mathrm{RC}$ quantitative assessment can only be ascribed to the drainage layer properties. It was found that the difference in the GRs' hydrological performances in the case of low initial VW (group B) is almost negligible (7\%). This circumstance would probably entail that for this particular type of event, regardless of the rainfall properties, the main role in the retention process is played by the vegetation and substrate layers. Differences in the hydrological behavior increase up to $26 \%$ in the case of high initial VW (group C). It is likely that in the case of high initial VW, the faster drainage from the substrate to the drainage layer sees the drainage layer largely involved in the retention process. The GR2, which has a larger retention capacity than the GR1, exhibits the best performance for this specific case.

The severity of the rainfall events, as described by the return period, was only accidentally studied for the case study, as only one (occurred on 22 May 2018) of the thirty-five selected rainfall events featured a high return period of 10 years. The retention coefficients for this particular event appeared significant, amounting to 58\% and 53\% respectively for GR1 and GR2. This particular event occurred with low initial VW conditions, which could have been the reason for the significant retention regardless of the rainfall severity. A longer monitoring period would probably increase the probability of facing rainfall events with longer return periods in order to detect the relevant GRs' hydrological performances. However, as a future perspective, indoor experiments under controlled laboratory conditions have been planned to specifically fill the observational gaps from this point of view.

A future work perspective is represented by the introduction of the evapotranspiration process into the definition of the retention characteristics of the green roof. Given the relationship between 
evapotranspiration losses and soil water content, it will be possible to replace VW with an index of the evapotranspirated volume, which may depend on the characteristics of the rain event [31]. In this way, it will be possible to organize a tool for the prediction of the hydrological performance of a green roof simply based on rainfall properties.

Author Contributions: A.L. conceived and designed the experiments; R.D. and M.M. performed the experiments; all the authors analyzed the data; all the authors contributed to writing the paper; A.L. reviewed the paper.

Funding: The authors will to thank the anonymous reviewers for their helpful comments. The authors also gratefully acknowledge funding support provided through the Instruction, University and Research Italian Ministry (MIUR) under the grant 300393FRB17 and 300393FRB18 and through the Civil Engineering Department of the University of Salerno who granted the necessary funding support for the experimental site construction.

Conflicts of Interest: The authors declare no conflict of interest.

\section{References}

1. Rozos, E.; Butler, D.; Makropoulos, C. An integrated system dynamics-Cellular automata model for distributed water-infrastructure planning. Water Sci. Technol. Water Supply 2016, 17, 1519-1527. [CrossRef]

2. Versini, P.A.; Kotelnikova, N.; Poulhes, A.; Tchiguirinskaia, I.; Schertzer, D.; Leurent, F. A distributed modelling approach to assess the use of Blue and Green Infrastructures to fulfil stormwater management requirements. Landsc. Urban Plan. 2018, 173, 60-63. [CrossRef]

3. Rozos, E.; Makropoulos, C.; Maksimovic, C. Rethinking urban areas: An example of an integrated blue-green approach. Water Sci. Technol. Water Supply 2013, 13, 1534-1542. [CrossRef]

4. Mentens, J.; Raes, D.; Hermy, M. Green roofs as a tool for solving the rainwater runoff problem in the urbanized 21st century. Landsc. Urban Plan. 2006, 77, 217-226. [CrossRef]

5. Li, W.C.; Young, K.K.A. A comprehensive study of green roof performance from environmental perspective. Int. J. Sustain. Built Environ. 2014, 3, 127-134. [CrossRef]

6. Knapp, S.; Schmauck, S.; Zehnsdorf, A. Biodiversity Impact of Green Roofs and Constructed Wetlands as Progressive Eco-Technologies in Urban Areas. Sustainability 2019, 11, 5846. [CrossRef]

7. Simmons, M.T.; Gardiner, B.; Windhager, S.; Tinsley, J. Green roofs are not created equal: The hydrologic and thermal performance of six different extensive green roofs and reflective and non-reflective roofs in a sub-tropical climate. Urban Ecosyst. 2008, 11, 339-348. [CrossRef]

8. Wang, X.; Tian, Y.; Zhao, X.; Peng, C. Hydrological performance of dual-substrate-layer green roofs using porous inert substrates with high sorption capacities. Water Sci. Technol. 2017, 75, 2829-2840. [CrossRef]

9. Akter, M.; He, J.; Chu, A.; Huang, J.; van Duin, B. A Review of Green Roof Applications for Managing Urban Stormwater in Different Climatic Zones. Sustainability 2018, 10, 2864. [CrossRef]

10. Schultz, I.; Sailor, D.; Starry, O. Effects of substrate depth and precipitation characteristics on stormwater retention by two green roofs in Portland OR. J. Hydrol. 2018, 18, 110-118. [CrossRef]

11. Berndtsson, J. Green roof performance towards management of runoff water quantity and quality: A review. Ecol. Eng. 2010, 36, 351-360. [CrossRef]

12. Chenot, J.; Gaget, E.; Moinardeau, C.; Jaunatre, R.; Buisson, E.; Dutoit, T. Substrate Composition and Depth Affect Soil Moisture Behaviour and Plant-Soil Relationship on Mediterranean Extensive Green Roofs. Water 2017, 9, 817. [CrossRef]

13. Ferrans, P.; Rey, C.V.; Pérez, G.; Rodriguez, J.P.; Diaz-Granados, M. Effect of Green Roof Configuration and Hydrological Variables on Runoff Water Quantity and Quality. Water 2018, 10, 960. [CrossRef]

14. Baryla, A.; Karczmarczyk, A.; Bus, A. Role of Substrates Used for Green Roofs in Limiting Rainwater Runoff. J. Ecol. Eng. 2018, 19, 86-92. [CrossRef]

15. Brandão, C.; Cameira, M.D.R.; Valente, F.; Cruz de Carvalho, R.; Paço, T.A. Wet season hydrological performance of green roofs using native species under Mediterranean climate. J. Ecol. Eng. 2017, 102, 596-611. [CrossRef]

16. Hilten, R.N.; Lawrence, T.M.; Tollner, E.W. Modeling storm water runoff from green roofs with HYDRUS-1D. J. Hydrol. 2008, 358, 288-293. [CrossRef]

17. Mobilia, M.; Longobardi, A.; Sartor, J.F. Including A-Priori Assessment of Actual Evapotranspiration for Green Roof Daily Scale Hydrological Modelling. Water 2017, 9, 72. [CrossRef] 
18. Chai, C.T.; Putuhena, F.J.; Selaman, O.S. A modelling study of the event-based retention performance of green roof under the hot-humid tropical climate in Kuching. Water Sci. Technol. 2017, 76, 2988-2999. [CrossRef]

19. Sartor, J.; Mobilia, M.; Longobardi, A. Results and findings from 15 years of sustainable urban storm water management. Int. J. Saf. Secur. Eng. 2018, 8, 505-514. [CrossRef]

20. Nawaz, R.; McDonald, A.; Postoyko, S. Hydrological performance of a full-scale extensive green roof located in a temperate climate. Ecol. Eng. 2015, 82, 66-80. [CrossRef]

21. Soulis, K.X.; Ntoulas, N.; Nektarios, P.A.; Kargas, G. Runoff reduction from extensive green roofs having different substrate depth and plant cover. Ecol. Eng. 2017, 102, 80-89. [CrossRef]

22. Todorov, D.; Driscoll, C.T.; Todorova, S. Long-term and seasonal hydrologic performance of an extensive green roof. Hydrol. Process. 2018, 32, 2471-2482. [CrossRef]

23. Sims, A.W.; Robison, C.E.; Smart, C.C.; Voogt, J.A.; Hay, G.J.; Lundholme, J.T.; Powers, B.; O'Carroll, D.M. Retention performance of green roofs in three different climate regions. J. Hydrol. 2016, 542, 115-124. [CrossRef]

24. Stovin, V.; Vesuviano, G.; Kasmin, H. The hydrological performance of a green roof test bed under UK climatic conditions. J. Hydrol. 2012, 414-415, 148-161. [CrossRef]

25. Mobilia, M.; Longobardi, A. Smart Stormwater Management in Urban Areas by Roofs Greening. In Computational Science and Its Applications_ICCSA 2017; Gervasi, O., Murgante, B., Misra, S., Borruso, G., Torre, C.M., Rocha, A.M., Taniar, D., Apduhan, B.O., Stankova, E., Cuzzocrea, A., et al., Eds.; Lecture Notes in Computer Science; Springer: Cham, Switzerland, 2007; Volume 1046, pp. 455-463.

26. Mobilia, M.; D'Ambrosio, R.; Longobardi, A. Climate, soil moisture and drainage layer properties impact on green roofs in a Mediterranean environment. In Frontiers in Water-Energy-Nexus-Nature-Based Solutions, Advanced Technologies and Best Practices for Environmental Sustainability; Naddeo, V., Balakrishnan, M., Choo, K.H., Eds.; Springer: Cham, Switzerland, 2020; pp. 169-171.

27. Mobilia, M.; Longobardi, A. Event Scale Modeling of Experimental Green Roofs Runoff in a Mediterranean Environment. In Frontiers in Water-Energy-Nexus-Nature-Based Solutions, Advanced Technologies and Best Practices for Environmental Sustainability; Naddeo, V., Balakrishnan, M., Choo, K.H., Eds.; Springer: Cham, Switzerland, 2020; pp. 153-156.

28. Krasnogorskaya, N.; Longobardi, A.; Mobilia, M.; Khasanova, L.F.; Shchelchkova, A.I. Hydrological Modeling of Green Roofs Runoff by Nash Cascade Model. Open Civ. Eng. J. 2019, 13, 163-171. [CrossRef]

29. Spectrum Technologies. WaterScout SM 100 Soil Moisture Sensor-Product Manuals; Spectrum Technologies: Plainfield, IL, USA, 2011.

30. Mobilia, M.; Califano, F.; Longobardi, A. Analysis of rainfall events driving MDHEs occurred in the Solofrana river basin, Southern Italy. Procedia Eng. 2015, 119, 1139-1146. [CrossRef]

31. Longobardi, A.; Khaertdinova, E. Relating soil moisture and air temperature to evapotranspiration fluxes during inter-storm periods at a Mediterranean experimental site. J. Arid Land 2015, 7, 27-36. [CrossRef] 